Desarrollo y ventajas competitivas de los negocios de franquicias comerciales en Bolivia http://doi.org/10.33996/revistaenfoques.v1i3.16

\section{DESARROLLO Y VENTAJAS COMPETITIVAS DE LOS NEGOCIOS DE FRANQUICIAS COMERCIALES EN BOLIVIA}

\author{
DEVELOPMENT AND COMPETITIVE ADVANTAGES OF COMMERCIAL \\ FRANCHISE BUSINESSES IN BOLIVIA
}

\author{
Edgar Olivares Álvares
}

\section{Resumen}

El propósito de la presente investigación fue analizar las características de las ventajas competitivas de los negocios de franquicias comerciales en Bolivia. El tipo de investigación corresponde al descriptivo explicativo. La recolección de datos se efectuó a través de técnicas cualitativas y cuantitativas. La técnica cualitativa que se emplea es el análisis y síntesis de la información recolectada, mientras que las técnicas cuantitativas fueron encuesta, entrevista y la sistematización de datos recolectados, además de la interpretación de información obtenida. Se pudo concluir que existen dos tipos de ventajas competitivas que las empresas bolivianas han desarrollado para incursionar en programas de franquicias. La primera y más extendida es la determinación del "costo de oportunidad" y la segunda ventaja competitiva es la creación de valor, que no todas las empresas bolivianas tienen, pero sí algunas que han logrado darles mayor valor agregado a sus productos o servicios como para desarrollar programas de franquicias en Bolivia.

Palabras clave: Negocios; franquicias; desarrollo y ventajas franquicias en Bolivia

\begin{abstract}
The purpose of this research was to analyze the characteristics of the competitive advantages of commercial franchise businesses in Bolivia. The type of research corresponds to the explanatory descriptive. Data collection was carried out through qualitative and quantitative techniques. The qualitative technique used is the analysis and synthesis of the information collected, while the quantitative techniques were survey, interview and systematization of data collected, in addition to the interpretation of information obtained. It was concluded that there are two types of competitive advantages that Bolivian companies have developed to venture into franchise programs. The first and most widespread is the determination of the "opportunity cost" and the second competitive advantage is the creation of value, which not all Bolivian companies have, but some that have managed to give added value to their products or services as to Develop franchise programs in Bolivia.
\end{abstract}

Key words: Business; franchises; development and franchise advantages in Bolivia

Artículo recibido abril 2017 | Arbitrado entre mayo-junio 2017 | Publicado en julio 2017

\section{Edgar Olivares Álvares}

gerenciageneral@cetbolivia.org

Universidad tecnológica Boliviana, Bolivia

Lic. en Ciencias de la Comunicación de la Universidad de Buenos Aires, Argentina. Diplomado en Educación Superior de la Universidad Mayor de San Andrés, Bolivia. Magister en Educación Superior de la Universidad Salesiana de Bolivia.

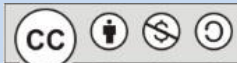

Revista Enfoques 


\section{INTRODUCCIÓN}

La apertura económica durante la década de los años noventa del siglo pasado conllevó a la eliminación de barreras cambiarias y arancelarias, lo que creó un ambiente propicio para el ingreso formal de las primeras franquicias internacionales a Bolivia, tales como McDonald's y otras que vinieron luego.

En la actualidad, los países y sus instituciones están frente a un mercado globalizado, internacionalizado, donde la oferta y demanda son soberanas, e imponen y obligan a tener nuevos comportamientos, nuevas conductas y la adopción de nuevas relaciones fundamentales de la economía.

En respuesta a este fenómeno, algunos empresarios de Bolivia comenzaron a estructurarse como franquicias, siendo pionera Pollos Copacabana en el sector de comida rápida. Las franquicias comerciales también han sufrido procesos de globalización, incluso las marcas y patentes se han internacionalizado mucho antes que el comercio de productos y servicios.

En 2012, el valor de las exportaciones bolivianas fueron de USD 9,416 millones, esto representó un incremento de 3,3\% con respecto al año previo. Cabe destacar que en los últimos cinco años las ventas al exterior aumentaron $8,1 \%$. Los principales productos exportados son gas natural, metales preciosos, zinc, aceites crudos de petróleo, entre otros.

Las importaciones se incrementaron $4,9 \%$ en promedio anual en los últimos cinco años. Estas compras totalizaron USD 6,053 millones en 2012, lo que representó una disminución de 21,1 \% con respecto al 2011. Sin embargo, los montos registrados en el presente año superaron a los obtenidos en los años previos a la crisis económica internacional.

La balanza comercial del país ha mostrado una tendencia positiva en los últimos años. En 2012 tuvo un saldo positivo de USD 3,363 millones, siendo este el mayor monto registrado durante el último quinquenio. Por otro lado, el intercambio comercial con el mundo registró un crecimiento promedio anual de $6,8 \%$ y en 2012 el monto ascendió a USD 15,469.

El intercambio comercial de servicios entre Bolivia y el mundo sumó USD 2,551 millones en 2012, con lo cual experimentó un aumento de $3,7 \%$ con respecto al año anterior. La tasa de crecimiento promedio anual fue de $13,9 \%$ en el último quinquenio. Es importante señalar que históricamente el país ha tenido una balanza comercial negativa, y en el último año este déficit alcanzó USD 906 millones.

Asimismo, en 2012 las importaciones de servicios fueron de USD 1,729 millones, lo que significó un aumento de $4,1 \%$ con respecto al año anterior. El crecimiento promedio anual, en los últimos cinco años, fue de $14,2 \%$, siendo en el periodo 2010 2011 cuando se registró el mayor incremento. Los servicios que registraron los mayores montos fueron los relacionados al transporte $(43,7 \%$ de participación) y el turismo $(17,9 \%)$.

La categoría "otros servicios" (distintos al transporte y turismo) cuenta con el 38,3\% restante y dentro de las principales categorías se encuentran los de seguro, de información (software, hardware y procesamiento de datos), comunicaciones y otros servicios de negocios.

El mercado boliviano ha empezado a incursionar en este modelo empresarial. Todo el proceso se ve favorecido por apertura de centros comerciales, presencia de mayor número de extranjeros y el aumento del poder adquisitivo de la población. Según un estudio realizado por ICEX, los sectores que mejor funcionan en este país son el gastronómico y el textil, los cuales son representados en su mayoría por 
franquicias argentinas, estadounidenses y bolivianas. Entre las más destacadas se encuentran United Colors of Benetton (Italia), Burger King, Kevingstone, La Martina, Dulces Jesse, entre otras.

La mayor demanda se localiza en los principales centros urbanos, donde se encuentra un número más elevado de habitantes. Las ciudades donde se han detectado un mayor número de franquicias son La Paz, Santa Cruz y Cochabamba; sin embargo, por necesidades de expansión, se han localizado en otras ciudades tales como Tarija, Sucre y Trinidad.

Actualmente, el país no cuenta con alguna ley de franquicias; por tanto, la relación contractual rige lo que las partes hayan pactado en el propio contrato, respetando las disposiciones del Código de Comercio y el Código Civil boliviano. La fuerza de la marca no es fundamental para el éxito en el mercado boliviano; por el contrario, la característica más importante es la capacidad de adaptación y de modificación del franquiciador.

El sector gastronómico está marcado por una fuerte competencia de restaurantes y cadenas locales. Además, los gustos gastronómicos en Bolivia son muy particulares, por lo que cualquier empresa que quiera incursionar en el negocio tendrá que adaptar su producto tanto en el gusto como en tamaño.

En el caso de las franquicias en el sector textil, se ha detectado que uno de los puntos en el que se da mayor énfasis es en el de atención al cliente. El franquiciado trata de cuidar mucho este aspecto hasta conseguir un buen equipo de ventas y lograr que el cliente se sienta asesorado personalmente.

Con respecto al público objetivo, se debe diferenciar el sector gastronómico del textil. En el primero, el alcance es mayor debido a que el público puede ser de clase alta o baja, y en el sector textil el campo se restringe al ciudadano boliviano de clase alta debido a que se establecen mayores precios.

Bolivian Food administra la franquicia de Subway, Burger King y La Quinta, esta última de comida criolla nacional. Alfredo Troche, gerente de Bolivian Food, dijo que están encaminando el producto nacional para venderlo como franquicia. Por su parte, hamburguesas Toby, que tiene 33 locales a escala nacional, y prevé abrir cinco más hasta fin de año, se encuentra en proceso de estandarización para vender su franquicia. En similar situación se encuentran Manjar de Oro y Hot, entre otras (ICEX, 2013).

En términos más concretos, el problema objeto de análisis viene relacionado con los anteriores párrafos de la siguiente manera: ¿cuáles son las ventajas competitivas de productos y servicios de empresas bolivianas existentes en el mercado nacional que contribuyen al desarrollo de franquicias comerciales?

Se planteó como objetivo general identificar las ventajas competitivas existentes en las empresas bolivianas que contribuyen al desarrollo de franquicias. $Y$ como objetivos específicos, analizar las características de las franquicias desarrolladas por empresas nacionales que lograron consolidar negocios de franquicias en Bolivia; identificar los requisitos propios de las empresas que han logrado desarrollar franquicias en Bolivia; establecer el tipo de negocios que tienen mejores perspectivas para el desarrollo de franquicias en Bolivia; determinar qué aspectos del proceso de desarrollo de franquicias se están cumpliendo actualmente en las empresas bolivianas que han optado por un programa de franquicias.

Para ello se formuló como hipótesis que la identificación de las ventajas competitivas de productos y servicios de empresas bolivianas existentes en el mercado nacional contribuye al desarrollo de franquicias comerciales, teniendo como variable 
independiente las ventajas competitivas de productos y servicios de empresas bolivianas existentes en el mercado nacional $y$, como variable dependiente, el desarrollo de franquicias comerciales.

Actualmente, el comercio de franquicias en el mundo es una de las actividades económicas más atractivas y rentables para los empresarios de diferentes rubros, que, sin embargo, en Bolivia se está desarrollando lentamente y sin ningún plan o estrategia empresarial o de fomento estatal.

\section{MATERIALES Y MÉTODOS}

En lo que respecta a la metodología, la investigación tuvo un enfoque mixto, es decir, cualitativo y cuantitativo. El método empleado es deductivo, ya que se parte de conocimientos generales científicos para aplicarlos a un sector de estudio, que son las empresas bolivianas que han desarrollado franquicias.

El tipo de investigación corresponde al descriptivo-explicativo. Descriptivo, debido a que tiene como propósito: "describir situaciones y eventos, es decir, buscar especificación de las propiedades importantes de persona, grupo, comunidades o cualquier otro fenómeno que sea sometido a análisis y medir el grado de relación que existe entre dos o más variables" (Hernández y otros, 1997, s/n). En este caso, se describen los diferentes elementos involucrados en el desarrollo y comercio de franquicias, así como los factores competitivos que inciden en la franquiciabilidad de un negocio.

Se empleó un tipo de investigación explicativo, porque se intenta mostrar no solamente los procesos de desarrollo de franquicias en Bolivia y los factores competitivos que inciden en el desarrollo de franquicias, sino más que todo las causas y ventajas de las franquicias en Bolivia.
La recolección de datos se llevó a cabo a través de técnicas cualitativas y cuantitativas. La técnica cualitativa que se emplea es el análisis y síntesis de la información recolectada, mientras que las técnicas cuantitativas empleadas fueron las encuestas, las entrevistas y la sistematización de datos recolectados, además de la interpretación de información obtenida. Las unidades de estudio fueron las empresas paceñas que han logrado o están en proceso de desarrollar y comercializar franquicias con empresarios extranjeros $y$ nacionales.

Dentro de la unidad de análisis, se pudo distinguir una población de propietarios y/o socios de empresas que lograron desarrollar franquicias y las han comercializado con empresarios nacionales o extranjeros. Según la Cámara de Franquicias (Cafran), actualmente en Bolivia existen 300 empresas que han desarrollado franquicias en Bolivia.

La recolección de datos fue efectuada a través de tres técnicas de investigación: la revisión documental, la encuesta y la entrevista.

\section{RESULTADOS Y DISCUSIÓN}

Dadas las limitaciones de páginas previstas para artículos como el que se está presentando, se ha querido resumir en el siguiente cuadro los resultados de la encuesta aplicada a socios, propietarios y/o ejecutivos de empresas que han desarrollado franquicias o se encuentran en su proceso de desarrollo. 
Cuadro 1. Ítems y análisis de los resultados

ÍTEMS

¿Su empresa ha

desarrollado o está en

proceso de hacer una

franquicia?

\section{RESULTADOS}

El $96 \%$ de los encuestados respondieron afirmativamente, es decir, que ya han desarrollado algún tipo de franquicia, no necesariamente comercial, o se encuentran en su proceso de desarrollo. Algunas de estas empresas ya han desarrollado la franquicia y se encuentran en posibilidades de comercializarlas. El $4 \%$ que no contestó afirmativamente, aclaró que recién se encuentra analizando la posibilidad de desarrollar una franquicia, debido a que considera que su empresa tiene productos y/o servicios que tienen el suficiente potencial para desarrollar una franquicia.

El $60 \%$ de los encuestados respondieron que han desarrollado una franquicia con base en el estudio y determinación de costo de oportunidad de la empresa en el mercado como estrategia competitiva. Para ello, los propietarios analizan la oportunidad del desarrollo de una

¿Con base en qué ventajas competitivas considera que está desarrollando su franquicia? franquicia en el mercado o mercados al cual se pretenden dirigir, determinando costos y beneficios. El $16 \%$ de los encuestados respondieron que emplearon la estrategia de creación de valor, que generalmente ha consistido en la generación de uno varios aspectos distintivos del producto o servicio que la diferenciad de la competencia y que marca un sello propio para la empresa. Y el $11 \%$, respondió que aplicó de alguna manera ambas estrategias para desarrollar un factor o recurso de creación de valor y analizar adicionalmente el costo de oportunidad.

Solamente el $27 \%$ de los encuestados respondieron que actualmente la estructura del mercado del negocio de su empresa favorece la creación de franquicias. El $73 \%$ restante considera que la estructura del mercado no es favorable para el desarrollo de franquicias. En relación con los motivos o razones por las cuales los encuestados consideraban que la estructura del mercado del negocio de su empresa favorece la creación de franquicias, el $15 \%$ respondió que se tiene la "posibilidad de replicar el negocio en el mercado".
¿Cree usted que la estructura del mercado favorece el negocio de su empresa como para crear franquicia?

El $44 \%$ de los encuestados respondieron que la rentabilidad de su actividad empresarial incentiva a la creación de franquicias. En relación con los motivos o razones para que se presente esta situación, el $20 \%$ de los inversionistas señala que en su actividad empresarial existen

¿La rentabilidad de su actividad empresarial incentiva a la creación de franquicias? "inversionistas que conocen del negocio", por lo que pueden reconocer un negocio exitoso de uno que no lo es, lo cual es determinante para el desarrollo posterior de franquicias. En segundo lugar, los encuestados mencionan que en sus actividades empresariales se presentan "excedentes para su reinversión", es decir, recursos con los cuales se pueden realizar a su vez nuevos emprendimientos, entre los cuales se puede presentar el desarrollo de franquicias, aunque también la incursión en otros negocios, según desee o no diversificar el riesgo. 
Los encuestados consideran que el factor que incide en mayor grado en la rentabilidad de su actividad empresarial es "la segmentación y discriminación de consumidores" (58\%). En segundo lugar, mencionan a las "externalidades de la red" (20\%), es decir, factores de orden externo a

En su opinión, ¿̇qué factores inciden en la rentabilidad de su actividad empresarial? la empresa que puede favorecer la rentabilidad de su negocio. Posteriormente, se menciona el "grado de rivalidad en el mercado" (8 \%), que contribuye a la rentabilidad del negocio, debido a que los empresarios se ven incentivados a buscar opciones para afrontar a la competencia, y, finalmente, conseguir el éxito deseado. En la categoría "otros", los encuestados mencionaron el mercado potencial que tiene la empresa o negocio del encuestado, lo cual puede hacer rentable el negocio en la medida en que se aprovechen las oportunidades que brinda el mercado.

El $78 \%$ de los encuestados respondieron que en sus empresas han desarrollado o se encuentran interesados en desarrollar franquicias comerciales. $Y$ en segundo lugar, $13 \%$ se inclina por las franquicias de

¿Qué tipo de franquicia ha desarrollado o está interesado en desarrollar?

Con qué requisitos considera que cuenta su negocio como para desarrollar franquicias? servicios. En menor porcentaje (5\%), los encuestados prefieren franquicias industriales y $4 \%$ ninguna. Estos resultados confirman la información obtenida en relación con las preferencias por el tipo de franquicias que se desarrollan en Bolivia, en donde tanto los empresarios nacionales como los potenciales inversionistas en franquicias prefieren las de tipo comercial, debido a que su negociación y colocación es más accesible y fácil de lograr.

La mayoría de los encuestados ( $25 \%$ ) considera que su negocio cuenta con el requisito de "negocio probado", que se encuentra entre los más importantes para el desarrollo de franquicias; $y$, en segundo lugar, mencionaron que su negocio ha alcanzado "notoriedad en el mercado" (20 $\%)$, otro requisito importante para el desarrollo de franquicias. Otros requisitos que los propietarios señalaron que cuenta su negocio para el desarrollo de franquicias son: "signos distintivos del negocio" (15\%), "propiedad legal de la marca" (9\%), "imagen" (4\%) y "marca" (4\%). Solamente un $5 \%$ de los encuestados respondieron que sus negocios cuentan con todos los requisitos mencionados entre las opciones de la pregunta, que se consideran importantes para el desarrollo de franquicias.

Entre otros requisitos mencionados por los encuestados que cuenta su negocio se encuentra el de "negocio transmisible" (40\%), que es uno de los más importantes para el desarrollo de franquicias; además, el $31 \%$

¿Qué otros requisitos considera que son atractivos para el desarrollo de franquicias en su negocio? señala que el negocio en el que se desenvuelve otorga "rentabilidad para todas las partes", requisito que convierte a las empresas en potenciales atractivas para el desarrollo de franquicias. Otros requisitos mencionados son: "concepto diferenciado del negocio" (16 \%) y "existencia de un mercado de consumidores e inversionistas" (5\%). Solamente $4 \%$ de los encuestados respondieron que sus negocios cuentan con todos los otros requisitos mencionados entre las opciones de la pregunta, que se consideran importantes para el desarrollo de franquicias. 
ÍTEMS

¿Cuenta con un plan estratégico para el desarrollo de franquicias?

\section{RESULTADOS}

El $69 \%$ de los encuestados respondió que cuenta con un plan estratégico para el desarrollo de franquicias, fase que se constituye en la base de todo programa o intención de desarrollo de franquicias para las empresas que se encuentran enfrascadas en este propósito. El 31 \% señaló que no tiene plan estratégico, aunque corresponde a empresas que se encuentran en una fase inicial del proceso de desarrollo de franquicias.

El $55 \%$ de los encuestados respondieron que no han desarrollado manuales de franquicias y tampoco han llevado procesos de capacitación del personal. En contrapartida, $45 \%$ de los encuestados respondieron que sí llevaron a cabo estos procesos, considerados importantes en el desarrollo de franquicias empresariales. Estos resultados muestran que la mayoría de los encuestados no cuentan con manuales de franquicias ni han impartido capacitación al personal, lo cual significa que puede que estos procesos no sean necesariamente indispensables para el desarrollo de franquicias o que ciertas empresas que se encuentran inmersas en el desarrollo de franquicias, todavía no han llegado a estas fases o las están postergando.

El $60 \%$ de las empresas que han llevado a cabo procesos de desarrollo de franquicias cuenta con una redacción elaborada de los contratos de franquicia. $40 \%$ respondió, por otra parte, que aún no cuenta con la redacción de estos contratos. Estos resultados muestran que existe un mayor interés de parte de los empresarios interesados en el desarrollo de franquicias en la fase de redacción de contratos, aunque muchas empresas que se encuentran en pleno proceso todavía no han concretado este proceso.

Solamente $35 \%$ de las empresas que han llevado a cabo procesos de desarrollo de franquicias respondió que cuenta con un sistema de control de franquicias. El 65 \% respondió, por otra parte, que aún no cuenta con un sistema de control de franquicias en sus empresas.

\section{Discusión}

Etimológicamente, se puede decir que la franquicia hace referencia a agrupaciones urbanas surgidas en la Edad Media, favorecidas con privilegios especiales llamadas "franquicias", en honor al origen franco o francés de la mayoría de sus componentes. Por otra parte, antes de la era de las peregrinaciones, el gentilicio germánico franco, de los conquistadores de la Galia, se había popularizado como sinónimo de libre, exento, noble, etc. Franquicia, como franqueza y otros derivados, alude claramente a los francos.

El término franquicia cuenta con varias definiciones, propuestas por diferentes autores, quienes a su vez coinciden diversos aspectos en común. A fin de proporcionar una visión amplia del significado de franquicia, se han retomado los siguientes conceptos:

La franquicia es un proceso en el que existe una colaboración conjunta entre empresas legales, donde se comercializan productos, servicios y/o tecnología (Jiménez, 2006).

Franquicia es, desde el punto de vista técnico, un modo de distribución o de comercialización de un determinado producto o servicio, en el que intervienen dos partes: la poseedora de la marca y de un gerenciamiento prefijado (el franquiciante) 
la interesada en comprarlos (el franquiciado) (Becerra, 2003).

Para Artola (2002), la franquicia es un tipo de contrato utilizado en comercio por el que una parte llamada franquiciador cede a otra llamada franquiciado la licencia de una marca, así como métodos de hacer negocios a cambio de una tarifa periódica conocida como royalty. No existe un consenso acerca del concepto de franquicia; sin embargo, se acepta de manera general que se trata de un contrato por el cual un comerciante (franquiciante) otorga a otro (franquiciatario) la licencia, para que venda productos o servicios de su titularidad. Generalmente, se paga una cuota por este privilegio, más una regalía (royalty) sobre las ventas.

Para otros es un sistema de distribución comercial llevado a cabo por empresas independientes y con una organización piramidal basada en una relación contractual, la que engloba la transmisión de un know how, la licencia y usos de una marca, asistencia técnica y contable, bajo control del otorgante y de conformidad con un método preestablecido por él, en contraprestación de lo cual se paga una cuota y otras prestaciones adicionales (Sánchez, 2005).

Según Meyer (2001), la franquicia es un acuerdo contractual mediante el cual una compañía matriz (franquiciante) le concede a una pequeña compañía (franquiciatario) el derecho de hacer negocios en condiciones específicas. De acuerdo con Meyer, el franquiciante tiene el derecho de nombre o de marca registrada y le vende el derecho a un franquiciatario, lo cual se conoce como licencia de producto, que en la forma más compleja el formato de licencia de negocio es una relación más amplia y continua que existe entre dos partes, donde a menudo comprende un rango completo de servicios, incluyendo selección de sitio, entrenamiento, suministro de productos, planes de marketing y también financiamiento.

Después de que el período de la franquicia ha concluido, el franquiciador o franquiciatario tiene el derecho de recompra o reventa de la unidad (Stone, 1991). Desde una escala gubernamental, la franquicia se entiende como la concesión otorgada por un organismo del gobierno a un individuo, a una sociedad colectiva $\mathrm{o}$ a una sociedad anónima, para utilizar una sociedad pública, una calle o una carretera. La franquicia puede ser por un término fijo de años, por un período indeterminado o a perpetuidad (Kennedy, 2007).

Kotler (2005) añade que la franquicia es un convenio con el concesionario en el mercado extranjero, que ofrece el derecho de utilizar el proceso de fabricación, la marca, la patente, el secreto comercial y otros puntos de valor, a cambio de honorarios o regalías.

Hoy en día el sistema de franquicias se encuentra en evolución y crecimiento constante. En este sentido, cabe señalar que existen una serie de ventajas y desventajas que se presentan para las partes involucradas en el negocio de las franquicias (Miquel, 2006).

El término ventaja competitiva no tiene una definición precisa, existiendo más bien una serie de opiniones particulares basadas en la experiencia de cada autor. A modo de ejemplo, Porter (2005) plantea que "para que exista una ventaja competitiva el valor que una firma es capaz de crear para sus consumidores debe ser mayor al costo que tenga para la firma la creación de dicho valor, argumentando que el valor es lo que los consumidores están dispuestos a pagar" (s/n). 
Peteraf (1993), por su parte, plantea que una empresa tiene una ventaja competitiva cuando la heterogeneidad de sus recursos y capacidades le entrega la posibilidad de tener un desempeño superior al de sus competidores.

Saloner y otros (2001) plantean que existe una ventaja competitiva, ya sea cuando una empresa produce un producto o servicio que sus clientes valoran más que aquellos producidos por sus competidores o cuando producen sus bienes o servicios a un costo menor al de sus competidores.

De las definiciones anteriores se concluye que el concepto de ventaja competitiva está asociado con valor agregado, pero dichas definiciones parecen ser muy generales como para proveer herramientas claras a los administradores de empresas para evaluar su existencia, y algunas de ellas pueden estar no considerando - al menos explícitamenteciertos elementos centrales relacionados con los determinantes de la creación de valor. Así es como la definición de Porter (2005), que argumenta que el valor creado por una firma corresponde a lo que los consumidores están dispuestos a pagar, falla en reconocer que la disposición a pagar por un bien o servicio no es necesariamente equivalente al precio que la empresa es capaz de obtener por dicho bien o servicio en el mercado, que es lo que finalmente importa para la empresa.

En conclusión, el concepto de ventaja competitiva está relacionado con el de creación de valor. Para que se cree un valor económico se requiere que el retorno obtenido por la empresa sea mayor al costo de los recursos invertidos en ella, incluyendo el costo de capital. En términos más específicos, se creará valor si el precio del producto -que es lo que efectivamente recibe la empresa- es mayor al costo de oportunidad de proveerlo, por lo que diremos que existe una ventaja competitiva cuando este sea el caso (Makadok, 2001).

El costo de oportunidad de proveer el producto debe incluir todos los costos asociados a su producción y venta, más una remuneración por el capital utilizado, la que depende, al menos en parte, del riesgo del producto o negocio. Nótese que en este caso no se está comparando la rentabilidad de la empresa con el promedio de la industria, sino que con el costo de oportunidad de los recursos utilizados.

Para que una empresa tenga una ventaja competitiva no basta con que posea recursos o capacidades heterogéneas o que desarrolle un conjunto de actividades distintas a las que desarrollan otras empresas, sino que también requiere de lo que le entrega una muy buena rentabilidad de corto plazo, pero muy probablemente a costa de una sobreexplotación del recurso y menor rentabilidad, y de ciertas asimetrías que pueda ir formando y de condiciones del tipo de competencia y estructura del mercado en que se encuentra (Makadok, 2001).

\section{CONCLUSIONES}

A continuación, se exponen las conclusiones de la investigación que dio origen a este artículo, considerando los objetivos trazados al inicio del estudio. El objetivo general fue planteado en los siguientes términos: "Identificar las ventajas competitivas existentes en las empresas bolivianas que contribuyen al desarrollo de franquicias".

En la investigación de campo se pudo establecer que existen dos tipos de ventajas competitivas que las empresas bolivianas han desarrollado para incursionar en programas de franquicias. La primera y más 
extendida es la determinación del "costo de oportunidad", que se basa esencialmente en el aprovechamiento de un negocio exitoso que se desea aprovecharlo y explotarlo en forma de franquicias en otros mercados. La mayoría de las empresas opta por hacerlo inicialmente en el interior del país, como es el caso de las empresas nacionales de comida rápida; y otras con mayor perspectiva y visión de negocios lo hace en otros países, preferentemente de Sudamérica como Perú y Argentina; y otras empresas se establecieron en Estados Unidos, como es el caso de las empresas de confecciones y moda Beatriz Canedo Patiño y Liliana Castellanos.

La segunda ventaja competitiva es la creación de valor, que no todas las empresas bolivianas tienen, pero sí algunas que, con base en esquemas de innovación y adaptación al mercado, han logrado darles mayor valor agregado a sus productos 0 servicios como para desarrollar programas de franquicias en Bolivia. A esta categoría pertenecen las empresas señaladas anteriormente en el rubro de la moda y otras como ser cadenas de joyería con base en plata y piedras preciosas como la bolivianita.

Ahora bien, la ventaja competitiva de "creación de valor" no es suficiente por sí sola en la mayoría de los casos para desarrollar franquicias, aunque inicialmente en las primeras franquicias en el mercado interno haya tenido resultados. Sin embargo, para incursionar en otros mercados, tanto internos como externos, es necesario complementar esta ventaja competitiva con el análisis del costo de oportunidad.

Con respecto a los objetivos específicos:

1. Analizar las características de las franquicias desarrolladas por empresas nacionales que lograron consolidar negocios de franquicias en Bolivia. La mayoría de las franquicias desarrolladas en este país pertenecen al rubro de comida rápida, con algunas experiencias importantes que llegaron incluso a países vecinos, como Perú y Argentina. Estas empresas nacionales ofrecen principalmente, pollos a la broaster, pollos al spiedo, hamburguesas, comida típica nacional y pizzas. La mayoría de estas franquicias nacieron de las experiencias exitosas de sucursales de los mencionados negocios de comida rápida en zonas o barrios alternativos a la localización de las empresas matrices, es decir, sobre la base de un análisis del costo de oportunidad.

Los negocios de moda y joyería muestran un desarrollo inicial diferente, debido a que el valor agregado y la creatividad fueron los principales recursos para consolidar el negocio, complementado por visitas cada vez más frecuentes a ferias, muestras, eventos y/o exposiciones nacionales $y$, principalmente, internacionales, en emporios de la moda como Nueva York, que con el tiempo se consolidaron en forma de franquicias.

2. Identificar los requisitos propios de las empresas que han logrado desarrollar franquicias en Bolivia. En la investigación de campo se pudo determinar que la mayoría de los empresarios señala que su negocio cuenta con el requisito de "negocio probado" como uno de los requisitos más importantes para el desarrollo de franquicias. Además, se resalta la notoriedad del negocio en el mercado como otro requisito importante para el desarrollo de una franquicia.

Otros requisitos que los propietarios señalaron que se presentan en su negocio para el desarrollo de franquicias son: signos distintivos del negocio, propiedad legal de la marca, imagen y marca. Sin embargo, el 
éxito de una franquicia está dado por un conjunto de requisitos, más que uno en especial. Sin embargo, en el estudio de campo se determinó que solo $5 \%$ de los empresarios consideran que cuentan con todos los requisitos necesarios para el desarrollo de franquicias.

Entre otros requisitos mencionados por los empresarios en el estudio de campo, se encuentra el de negocio transmisible, que es uno de los más importantes para el desarrollo de franquicias, además de otro requisito considerado trascendental, como la posibilidad de que el negocio otorgue rentabilidad para todas las partes, requisito que convierte a las empresas en potenciales atractivas para el desarrollo de franquicias.

3. Establecer el tipo de negocios que tienen mejores perspectivas para el desarrollo de franquicias en Bolivia. A partir del análisis de los resultados del estudio de campo se puede concluir que en el mercado interno los negocios con mayores perspectivas de desarrollo de franquicias son aquellos en los cuales se presentan niveles altos de rentabilidad, que favorecen la ventaja competitiva del costo de oportunidad, es decir, negocios consolidados en rubros de comida rápida, comida típica, supermercados y farmacias.

En una perspectiva internacional, los negocios que aprovechan la ventaja competitiva de creación de valor, es decir, aquellas que desarrollan mayor agregado a los insumos, pueden desarrollar franquicias exitosas en mercados altamente competitivos, como es el caso de empresas dedicadas al rubro de la moda y joyería de plata y piedras típicas bolivianas.

4. Determinar qué aspectos del proceso de desarrollo de franquicias se están cumpliendo actualmente en las empresas bolivianas que han optado por un programa de franquicias. No todas las empresas que han desarrollado franquicias han cumplido con todas las fases del proceso de desarrollo de una franquicia. En el estudio de campo se pudo determinar que la disponibilidad de un plan estratégico para el desarrollo de franquicias es fase que se constituye en la base de todo programa o intención de desarrollo de franquicias para las empresas que se encuentran enfrascadas en este propósito. Esta fase es cumplida por un poco más de dos tercios de las empresas que conformaron la muestra.

El desarrollo de manuales de franquicias y procesos de capacitación del personal es efectuado por menos de la mitad de las empresas que llevaron a cabo el desarrollo de franquicias empresariales.

La mayoría de los encuestados no cuentan con manuales de franquicias $y$ tampoco han impartido capacitación al personal, lo cual significa que estos procesos no sean necesariamente indispensables para el desarrollo de franquicias, o que ciertas empresas que se encuentran inmersas en el desarrollo de franquicias todavía no han llegado a estas fases o las están postergando. Estas limitaciones pueden dar lugar posteriormente a problemas de sostenibilidad de las franquicias.

Más de la mitad de de las empresas que han llevado a cabo procesos de desarrollo de franquicias cuenta con una redacción elaborada de los contratos de franquicia, lo cual muestra que existe un mayor interés de parte de los empresarios, en la fase de redacción de contratos, aunque muchas empresas que se encuentran en pleno proceso todavía no han concretado este proceso. 
Finalmente, solo un poco más de un tercio de las empresas que han llevado a cabo procesos de desarrollo de franquicias respondió que cuenta con un sistema de control de franquicias. Esto permite deducir que incluso algunas de las empresas que han desarrollado franquicias no cuentan con sistemas de control de franquicias y marcas, debido a que dicho proceso es uno de los más controvertidos y requieren, como es el caso boliviano, de una legislación específica que actualmente no existe en el país y que la mayoría de las empresas tratan de subsanar especificando detalles de control de franquicias en los mismos contratos. Además, se observa un descuido por la protección de la marca.

\section{REFERENCIAS}

Artola, A. (2002). Franquicias. Barcelona: Ed. Prentice Hall-Hispanoamericana

Becerra, R. (2003). La franquicia como alternativa de inversión. Madrid: Ed. lespana

Feher, F. (2000). Hablemos de franquicias con franqueza. México: Editorial McGraw Hill

Hernández, R. y otros (1997). Metodología de la investigación. México: Ed. McGraw-Hill

Instituto de Comercio Exterior - ICEX (2013). Cinco franquicias bolivianas del sector alimentación comienzan su expansión internacional. Recuperado de: http://www.icex.es/icex/es/navegacionprincipal/todos-nuestrosservicios/informacion-demercados/paises/navegacionprincipal/noticias/4695163.html?idPais= BO

Jiménez, C. (2006). Guía fuerte, marca fuerte. México: Ed. Trillas

Kennedy, F. (2007). Estados financieros. México: Ed. Porrúa

Kotler, P. (1995). Dirección de mercadotecnia. México: Ed. McGraw-Hill

Makadok, R. (2001). Síntesis de la teoría sobre la capacidad dinámica de la creación de la renta. Strategic Management Journal 22(5): 387-402

Meyer, H. (2001). Marketing, ventas al por menor. México: Ed. Trupper

Miquel P., S. (2006). Distribución comercial. México: ESIC Editorial

Peteraf, M. (1993). Los factores de la ventaja competitiva. Strategic Management Journal, 14(3): 179-191

Porter, M (2005). Ventaja competitiva. Nueva York: Ed. Pearson

Saloner, G.; Shepard, A. y Podolny, J. (2001). Administración estratégica. Nueva York: Ed. Wiley

Sánchez, E. (2005). La franquicia, una oportunidad de negocios y de vida. México: Universidad de Santo Tomás

Stone, K. y otros (1991). Ventas al por menor. México: Ed. Trillas 